\title{
Access to Artificial Intelligence for Persons with Disabilities: Legal and Ethical Questions Concerning the Application of Trustworthy AI
}

\author{
Kristi Joamets \\ Archil Chochia \\ Department of Law \\ Tallinn University of Technology \\ Ehitajate tee 5 \\ Tallinn 19086, Estonia \\ Email:kristi.joamets@taltech.ee \\ Email: archil.chochia@taltech.ee
}

\begin{abstract}
Digitalisation and emerging technologies affect our lives and are increasingly present in a growing number of fields. Ethical implications of the digitalisation process have therefore long been discussed by the scholars. The rapid development of artificial intelligence $(\mathrm{Al})$ has taken the legal and ethical discussion to another level. There is no doubt that Al can have a positive impact on the society. The focus here, however, is on its more negative impact. This article will specifically consider how the law and ethics in their interaction can be applied in a situation where a disabled person needs some kind of assistive technology to participate in the society as an equal member. This article intends to investigate whether the EU Guidelines for Trustworthy $\mathrm{Al}$, as a milestone of ethics concerning technology, has the power to change the current practice of how social and economic rights are applied. The main focus of the article is the ethical requirements 'Human agency and oversight' and, more specifically, fundamental rights.
\end{abstract}

Keywords: artificial intelligence, digitalisation, ethics, ethics of technology, trustworthy Al 


\section{Introduction}

When explaining the complexity of determining an attitude toward technologies, Winston and Edelbach (2011) talk about two distinctive viewpoints-technopessimism and techno-optimism. While techno-pessimists focus on the negative aspects of technology and remain sceptical of technological solutions, technooptimists place emphasis on the benefits that technologies offer to the society and remain confident that technological solutions will solve the potential problems of technology. From the philosophical standpoint, this can be linked to two historical phases of technological analyses: the first being mid-twentieth-century classical hermeneutic critiques that focus on the negative effects on humans caused by modern technologies, and the second being an empirical approach looking at technology rather as elements determined socially via local use. A notable example of the first historical phase is philosopher Jacque Ellul, who believed that technology has developed at such a rapid speed that it could not be controlled by humans and therefore saw it as rather destructive (Ellul, 1964). On the other hand, the second phase approach shifts from general technology to a more nuanced approach, looking at local narratives, examining each technology individually and empirically, viewing it within the values and culture of those societies that use the given technology (see, e.g., Brey, 2010; Verbeek, 2011).

Similarly to the rest of the branches of philosophy, ethics derives from supposedly simple questions; nevertheless, as John Deigh (2010, p. 1) puts it, these questions only "seem simple, yet are ultimately perplexing". Digitalisation has been posing new such questions and, therefore, ethical implications of the digitalisation process have long been discussed by the scholars. Philosopher Deborah Johnson (2004, p. 69) speaks about information society as a society in which digital technologies shape the "human activity and social institutions". Digitalisation and emerging technologies affect our lives and are increasingly present in a growing number of fields (see, e.g., Ihde, 2020; Kerikmäe \& Rull, 2016; Rosenberg, 2020). Legal scholars are trying to find the best way to regulate the emerging technologies; also, substantial research is devoted to understanding the implications of emerging technologies on legal systems (Brownsword \& Goodwin. 2012; Kerikmäe et al., 2017; 2018). However, while both of the above approaches can be found in current scholarly discussion on the ethical aspects of technology, the emphasis is on the "continuity of persons and technology with the rest of the nature" (Parsons, pp. 6-9), while the widespread use of modern technologies, such as social media, Twitter, augmented reality, smartphones, 
internet and others, often resulting in moral and ethical issues, is not being paid enough attention to. (Deloitte, n.d.; Jobin et al., 2019)

The lack of literacy in digital ethics within our societies is alarming, as Beever et al. (2019, pp. 9-25) argue in their book Understanding Digital Ethics. They draw attention to the issues of technology control, agency and moral responsibility, drawing parallels with the famous ethical thought experiment in moral philosophy, the "trolley problem", for example when it comes to autonomous vehicles. The authors believe that digital ethics is a combination of two literacies: one being digital literacy—understanding of modern technologies and information, and the second ethical literacy—understanding and being motivated to act on the emerging ethical issues. And, consequently, in order to achieve a necessary understanding of digital ethics, it is absolutely crucial for one to possess a sufficient level of both digital literacy and ethical literacy.

The rapid development of artificial intelligence (AI) has taken the legal and ethical discussion to another level. AI has already replaced humans in many actions performed and this process of "preplacement" is going fast forward (see, e.g., Joamets \& Chochia 2020; Kerikmäe et al., 2020). Margit Sutrop (2020) discusses the possibility when AI exceeds human intelligence and the consequent need for aligning AI with human values, at the same time explaining what the challenges of such a process might be. Boucher (2018a, p. 5) refers to the impact of technology on "the future of humanity", and Kritikos (2018a) states that technologies induce new moral principles and ethics. This all proves that choosing the "right" way in regulating technology from the perspective of ethics is not an easy task, especially when it needs an interpretation based on values.

Nevertheless, in 2019, the EU Commission High-Level Expert Group on AI presented the Ethics Guidelines for Trustworthy Artificial Intelligence (hereafter Guidelines). The Guidelines have collected the most important values that "the whole Europe" should follow in the process of developing technology regarding AI, emphasising that "AI systems must be human-centric" (European Commission, 2019, pp. 4, 10,37) and that trustworthiness is a prerequisite for people and societies in developing, deploying and using AI systems (European Commission, 2019, p. 4).

Trustworthy AI is based on three components-it should be lawful, ethical and robust. All these components should be used or "work in harmony and overlap in their operations" (European Commission, 2019, p. 35) and at this would follow the "foundational values of respect for human rights, democracy and the rule of 
law" (European Commission, 2019, p. 4). This means that when determining the attitude towards technologies and attempting to unify the understanding of digital ethics as a whole, one has to start from the values deriving from fundamental and human rights, democracy and rule of law. Social and economic rights are closely related to the aforementioned principles and undoubtedly evolve human-centric nature. Additionally, the Guidelines give a non-exhaustive list of requirements that AI systems should meet in order to be trustworthy: human agency and oversight, technical robustness and safety, privacy and data governance, transparency, diversity, non-discrimination and fairness, societal and environmental well-being and accountability. (European Commission, 2019) This article focuses on the human agency and oversight based on the principle that AI systems should both act as enablers to a democratic, flourishing and equitable society by foster fundamental rights (European Commission, 2019).

There is no doubt that AI can have a positive impact on the society but considering how the lawfulness and ethics of trustworthy AI can be applied in a situation in which a disabled person needs some kind of assistive technology to participate in the society as an equal member raises several questions. Especially when asking how do economic and social rights interact in this?

The article is based on theoretical, social, economic and legal literature, political documents and legal acts, and investigates whether the Guidelines, as a milestone of ethics concerning technology, have the power to change the current practices in the application of social and economic rights. Or would the principles focusing on fundamental rights, provided in this document, remain a mere slogan which will never be followed because the nature of economic and social rights ${ }^{1}$ gives the states uncontrolled power to decide the degree to which the AI systems are human-centric and improve individual development and well-being and ensure equal access to social and economic opportunities (European Commission, 2019, p. 9).

The article begins with a discussion about the fundamental legal rights that trustworthy AI is based on and explains the place and role of economic and social rights in it. It explores the concept of social and economic rights, and explains how these rights are applied in practice and the main concerns in doing so. The article continues with an analysis of the implementation of trustworthy AI in practice in protecting disabled persons in applying economic and social rights. It discusses the main reasons why social rights have not reached the vulnerable

1 In this article, cultural rights as such have not been used in the discussion as the focus is only on economic and social rights. 
people in the extent they are entitled to and how this reflects the trustworthy AI principles in regard to ethics. The conclusion proposes suggestions about what states should consider when working out the policies and drafting legislation to be certain that trustworthy AI has been used.

\section{Legal rights as a basis for trustworthy Al: the role of economic and social rights}

\section{The Guidelines provide that}

Trustworthy AI has three principles which should be met throughout the system's entire life cycle: 1 . it should be lawful, complying with all applicable laws and regulations; 2 . it should be ethical, ensuring adherence to ethical principles and values; and 3. it should be robust, both from a technical and social perspective, since, even with good intentions, AI systems can cause unintentional harm. (European Commission, 2019, p. 2)

Trustworthy AI is based on fundamental rights and is reflected in ethical issues: "its central concern is to identify how AI can advance or raise concerns to the good life of individuals," it should improve individual development and wellbeing and ensure equal access to social and economic opportunities (European Commission, 2019, p. 9), giving an overwhelming protection to vulnerable groups ${ }^{2}$. Persons with disabilities belong to this group and should not be excluded from equal access to the benefits and opportunities that AI presents (European Commission, 2019, p. 10).

The Guidelines give legal grounds for the trustworthy AI mainly based on the EU law, such as EU treaties and the EU Charter of Fundamental Rights (EU Charter). Still, it also refers to international conventions. General European values such as fundamental rights, human rights, specifically human dignity, freedom of an individual, democracy, equality, non-discrimination and solidarity, and citizens' rights have been mentioned separately. (European Commission, 2019, p. 11)

2 However, it can be rather complicated to define vulnerable groups (see Arnardóttir, 2017). The Guidelines state that " $[\mathrm{n}] \mathrm{o}$ commonly accepted or widely agreed legal definition of vulnerable persons exists, due to their heterogeneity. What constitutes as a vulnerable person or group is often context-specific", and the Guidelines define a vulnerable group as "a group of persons who share one or several characteristics of vulnerability" (European Commission, 2019, p. 38). Persons with disability belong to the vulnerable group. 
The EU Charter provides that "The Union recognises and respects the right of persons with disabilities to benefit from measures designed to ensure their independence, social and occupational integration and participation in the life of the community" (Art. 26). Economic and social rights are human rights which are protected by several international conventions. The most important of them, the Universal Declaration of Human Rights, provides several economic and social rights, e.g., adequate standard of living, right to adequate food, right to health, right to social services, right to social security, etc., and the International Covenant of Economic, Social and Cultural Rights recognises economic, social and cultural rights as human rights. Economic, social and cultural rights are those human rights relating to the workplace, social security, family life, participation in cultural life, and access to housing, food, water, health care and education. (OHCHR, 2009, p. 1)

Economic and social rights are positive rights_ "an affirmative right to something" (Fares, 2019, p. 284) — but the obligations of states in relation to economic and social rights are expressed differently from treaty to treaty. In general, they are divided to respect (refrain from interfering with the enjoyment of the right), protect (prevent others from interfering with the enjoyment of the right) and fulfil (adopt appropriate measures towards the full realisation of the right) the rights (OHCHR, 2009, p. 11). States' obligations regarding economic and social rights have been explained also as "progressive realisation", which means that a state must take "appropriate measures towards the full realisation of economic and social rights to the maximum of their available resources" (OHCHR, 2009, p. 11). Often states have interpreted the available resources as if it is for them to decide whether at all and how much they allocate money for economic and social rights. It seems that they can always say that there are not enough available resources, and the case is closed.

Ferraz (2008) discusses that when answering the question what "available resources" means, one has to answer several

normative and empirical questions of an intractable nature, such as: how much of the wealth of society can the state legitimately extract through taxation?; what percentage of that amount ought to be devoted to each of the legitimate aims the state might pursue with these resources?; after this macro-allocation is resolved, how is the amount devoted to each of the interests protected by social rights to be allocated? (Ferraz, 2008, p. 587) 
In several states, economic and social rights are often protected also by the constitution. Since constitutional norms are abstract they do not determine what particular level of these social goods individuals are entitled to. Minkel and Prakash (2015, p. 11) argue that if economic and social rights are more like "directive principles" that the state should follow as an aim, then constitutional rights provide the specific justiciable right of an individual. As constitutional norms are also too general, the actual "individual justification" takes place at the level of a law act and this gives more options for a government to "play" with the distribution of the state's financial resources. It is not easy to determine the extent of such duty of the state: the content of economic and social rights does not have such a clear understanding, being "vaguely worded". (Ferraz, 2008, p. 585; OHCHR, n.d.)

The question whether a court can force a state to allocate (more) resources for a specific economic or social right has caused several discussions. However, states must "demonstrate that they are making every effort to improve the enjoyment of economic and social rights" even when they do not have enough resources (OHCHR, 2009, p. 14). Unfortunately, it still remains rather unclear what a minimum standard would be. It should be assumed that this standard can be different in different states and will be raised if the state's welfare will increase, or as Schwarz has explained: "the rights [which] may call on government to create something that was not there before" (Schwarz, 1993, p. 556). Considering the benefits that AI could give us, it is logical to derive from that that all groups of society should have access to these benefits or at least to a minimum standard of those. This minimum standard must be reflected already in a national policy providing specific rights to disabled persons.

There are several legal acts on international and EU level providing specific rights for disabled persons. The UN Convention on the Rights of Persons with Disabilities building "a comprehensive framework for the empowerment of people with disabilities" (Boucher, 2018b, p. 6) provides that

to undertake or promote research and development of, and to promote the availability and use of new technologies, including information and communications technologies, mobility aids, devices and assistive technologies, suitable for persons with disabilities, giving priority to technologies at an affordable cost (UN, 2006, Art. 4)

and 
accessible information to persons with disabilities about mobility aids, devices and assistive technologies, including new technologies, as well as other forms of assistance, support services and facilities (UN, 2006, Art. 4).

The European Pillar of Social Rights and the Charter of Fundamental Rights of the EU (Art. 21 and 26) and the Treaty on the Functioning of the European Union (Art. 10 and 19) cover the non-discrimination towards people with disabilities. Several legal acts, such as the European Accessibility Act, Medical Devices Directive, etc., provide rules applicable to persons with disabilities in labour, education, and health law.

If disabled persons have some rights and state obligations, there must be a mechanism to ensure these rights and obligations. To avoid a state declaring too easily that there are not enough resources raises a question of judicialisation of economic and social rights. Pastor y Camarasa argues that "judicialisation of economic, social and cultural rights is controversial — even though the solution to ensure the implementation of these rights has been seen through the court who obliges government to use resources in certain way, this can damage the separation of powers" (Pastor y Camarasa, 2016, pp. 216-217). Also Fares (2019, p. 281) states that "critics have long held that the enforcement of these rights in the courtroom would be inherently undemocratic and unmanageable". Minkler and Prakash (2015, p. 2) write that "wise or clever policy interventions, whether big or small, can only work to the extent that policymakers are willing to initiate, fund, monitor and enforce them." From the perspective of international law, a state must report about its compliance with international human rights law (Boyle, 2019, p. 111) but too often we see that "sustainable, people-centered and human rights based development" is missing (Crăciunean-Tatu, 2018, pp. 3031). The UN Human Rights Office writes on its webpage that the judiciary has the right to make decisions on economic and social rights and this is not "overstepping its constitutional role" (OHCHR, n.d.). The Council of Europe Commissioner for Human Rights has emphasised that it is an urgent matter to find "the right balance between the technological development and human rights protection" and that "human rights should be strengthened by AI, not undermined" (Council of Europe, 2019, pp. 5-6). Alemany and Gurumurthy (2019, p. 92) state that "we need full consideration of human rights in the context of AI design and operation".

This all proves that international law provides clear obligation to interpret trustworthy AI through the fundamental rights when granting social and economic rights to disabled persons. Even though "laws are mandatory guidelines 
while ethics are voluntary guidelines" (UKEssays, 2018), law and ethics are closely related because ethics is often reflected in laws and impacts our actions in following, implementing or even interpreting the laws. When talking about international conventions, these legal acts undoubtedly consist of values-a specific behaviour by a person which one can consider ethical behaviour. Authors of this article claim that the fact that certain ethical rules have found their way into a legal provision does not stop them from being an ethical norm. Ethical norm has simply got a stronger validity.

\section{Implementation of trustworthy $\mathrm{Al}$ in practice}

Despite the fact that all the abovementioned legal instruments support the protection of persons with disabilities, there are too many examples proving that they remain unattainable for disabled persons as the cost of the tools possibly causing "further social inequalities" is too high (Boucher, 2018b, p. 11). According to World Health Organisation,

200 million people with low vision who do not have access to assistive products for low vision. 75 million people who need a wheelchair and only $5 \%$ to $15 \%$ of those in need who have access to one. 466 million people globally experience hearing loss. Hearing aid production currently meets less than $10 \%$ of the global need. (WHO, 2018)

These numbers illustrate the amount of assistive technology needed, assuming that most of them are AI based. Undoubtedly, the issue is important not only from the state's but also from the EU's or even global perspective. Latonero (2018, p. 25) argues that although AI can influence the evolution of human rights and dignity in the future, currently existing assistive technology in Europe "are not always used to their full potential with regard to their integration into social services, health, education and employment", which means that "development and diffusion of assistive technology does not depend upon new high-tech solutions, but on social and political action towards inclusion through various means" (Boucher, 2018b, p. 12).

Persons with disabilities are not usually as effectively socially integrated, mobile and in employment as others. Such social exclusion can prohibit the individualised evaluation of the capacities and needs of vulnerable groups (see Arnardóttir, 2017). This can be changed if they had easier access to AI, and the 
AI systems had been developed specifically for their needs. As the AIs are able to learn algorithms to understand images, sound and even language, there are many options to adapt them to the needs of disabled persons. Unfortunately, quite often persons with disabilities are poor (see European Disability Strategy 2010-2020, $\operatorname{COM}(2010) 636$ final), which allows to assume that there will not be sufficient state support to help such people to get the AI or the state would not be interested in developing AI systems for persons with disabilities, thus hampering the "well-being of individuals, and their capacity to develop their full potential in life" (Malgesini et al., 2017, p. 3). The EU Disability Strategy 2010-2020 has noted that the "EU market for assistive devices is still fragmented and the devices are expensive. Policy and regulatory framework do not reflect the needs of people with disabilities adequately, neither for product nor service development". Considering these facts it seems inevitable, but at the same time doubtful, whether and how the individualised collective well-being that the AI systems should improve will be achieved. (European Commission, 2019, p. 11)

Based on the data of WHO, 1 billion people need 1 or more assistive products, whereas today, only 1 in 10 people in need have access to such products. However, with an ageing global population and a rise in non-communicable diseases, more than 2 billion people will need at least 1 assistive product by 2030 , with many older people needing 2 or more. (WHO, 2018) A large number of these products could be AI-based assistive products maintaining or improving an individual's functioning and independence, thereby promoting their wellbeing. When we are talking about AI-based assistive device, then the assistive technology can be an intelligent spoon, voice indicator, spectacles or hearing aid, assistance in bathing, it could monitor the behaviour of the invalid, offer social contact, take an invalid from the bed to wheelchair, it can be a guide dog, etc. (see Vercelli et al., 2017) There is no doubt that such devices would improve the well-being of disabled persons. Boucher names

accessibility as a human right, privacy by design, improving the informed consent process, a user-centred model of technology design, autonomy of choice to use AI, maintaining the availability of human care, developing appropriate ethics oversight structures, introducing a new classification system for AI and ensuring the safety of their use. (Boucher, 2018b, p. 15)

The list can be continued because there are too many aspects one should consider when developing AI. It is evident that AI systems "should not reinforce patterns of social inequality" (Kritikos, 2018b) but contribute to the well-being by an equal distribution of economic and social opportunity (European Commission, 
2019, p. 9) promoting the socio-economic benefit in the end. Unfortunately, as discussed in the previous part, the nature of economic and social rights can be obstacles to such distribution when applied incorrectly.

Before the government gives a green light to the AI development, it should decide which areas of the society should be developed the most or first regarding technology. As technological development needs a lot of financial resources, there should be transparent policies to promote one field or another. Addressing the principles of trustworthy AI could prove helpful here. Following the ethics requirements that an impact assessment of fundamental rights should be made in developing AI systems, the disabled persons' access to AI would be justified and thus become accessible through state policy.

As the changing society may also change the contents of fundamental rights, the decisions made for the disabled persons and AI-based assistive technologies may become outdated. Metzinger argues that

within the EU, AI-related productivity gains must be situated in a socially just manner. Obviously, past practice and global trends clearly point into the opposite direction: we have (almost) never done this in the past, and existing financial incentives directly counteract this recommendation. (Metziger, 2018, p. 30)

This is a "pacing problem" where technology develops so fast that the state cannot pace with it (Metzinger, 2018, p. 31). Will there be enough time to consider also social, ethical, demographic, environmental and regulatory trends? For example, individualistic lifestyle which leads to social deskilling and emotional isolation. Also, should there be limits to the integration of technologies into human bodies? What are the economic benefits when the disabled are helped to be socially integrated, mobile and in employment, and who should pay for that? The elderly differ from the young people in their needs of AI, however, the aging population in the EU undoubtedly means the need for more AIs as well. Crăciunean-Tatu writes that

The human person is the central subject of development and should be active participant and beneficiary of the right to development. Thus, the main consequences are the following: development policies and programmes must be centred on human beings and aimed at fulfilling their needs and expectations. (Crăciunean-Tatu, 2018, p. 30) 
This can raise questions whether a developed $\mathrm{AI}$ is ethical in the context of the Guidelines. However, even when a state is late with its policy, it is better to work out the policies on a national level to follow the trustworthy AI principles and promote access of disabled persons to equal benefits and opportunities rather than just to ignore the topic.

Following the principles of trustworthy AI requires a lot of analyses-legal, economic and social-to prove that there are reasons to make "robot legs and hands and else" for the disabled persons before participating in an "AI arms race" (Metzinger, 2018, p. 27), and before starting selling designed babies or find cure for everyone suffering from a mental disease. Disabled persons have many fundamental rights that the state is obliged to support. AI has so many ways to contribute to the development of assistive technology and gives a better opportunity than ever before to bring disabled persons back into the society to significantly reduce costs of disability care. If policies are made without these considerations, one cannot talk about ethical AI.

\section{Conclusion}

The rapid development of artificial intelligence (AI) has taken the legal and ethical discussion to a different level. The European Commission has worked out the Ethics Guidelines for Trustworthy Artificial Intelligence, providing the most important values "the whole Europe" should follow in the process of developing technology regarding AI. Some of the values among others are fundamental rights provided by the EU and international law, including those that should ensure equal access to social and economic opportunities (European Commission, 2019, p. 9) especially for persons with disabilities. This short analysis shows that despite a large number of legal norms providing overwhelming protection to disabled persons whether on the national, EU or international level, which should be followed in the development process of AI technology, the nature of economic and social rights can easily veto the implementation of such rights, and it is disputable whether ethical norms provided by the Guidelines have been followed. Even though in the process of making a state budget and delivering it between areas of state, and all this process follows the special rules to ensure the rule of law covering also the principles of trustworthy AI, especially human agency and oversight covering fundamental rights, it is widely known that allocating money from the state budget is a political decision. Still, if the principles of trustworthy 
$\mathrm{AI}$ are applied at the earliest stage of the policymaking process, it will be more likely that the persons with disabilities will get equal access to the benefits and opportunities of AI even when it is not instantly economically profitable for the state and such action can be considered ethical in the scope of the Guidelines.

\section{References}

Alemany, C. \& Gurumurthy, A. (2019), 'Governance of data and artificial intelligence,' Spotlight on Sustainable Development 2019, pp. 86-95. Retrieved from www.2030spotlight.org [accessed Apr 2021]

Arnardóttir, O. M. (2017), 'Vulnerability under Article 14 of the European Convention on Human Rights, innovation or business as usual?' Oslo Law Review, vol. 4, no. 3-2017, pp. 150-171. https://doi.org/10.18261/issn.2387-3299-2017-03-03

Beever, J.; McDaniel, R. \& Stanlick, N.A. (2019), Understanding Digital Ethics: Cases and Contexts, Abingdon: Routledge. https://doi.org/10.4324/9781315282138

Boucher, P. (2018a), 'Should we fear the future of artificial intelligence?' in P. J. Bentley, M. Brundage, O. Häggström \& T. Metzinger (eds.) In-depth Analyses, Science and Technology Options Assessment, Brussels: European Parliamentary Research Service, STOA, PE 614.547.

Boucher, P. (2018b), 'Assistive technologies for people with disabilities,' in P. J. Bentley, M. Brundage, O. Häggström \& T. Metzinger (eds.) In-Depth Analyses, Science and Technology Options Assessment, Brussels: European Parliamentary Research Service, STOA, PE 603.218.

Boyle, K. (2019), 'The future of economic, social and cultural rights in Scotland: prospect for meaningful enforcement,' Edinburgh Law Review, vol. 23, no. 1, pp. 110-116. https://doi.org/10.3366/elr.2019.0531

Brey, P. (2010), 'Philosophy of technology after the empirical turn,' Techné: Research in Philosophy and Technology, vol. 14, no. 1, pp. 36-48. https://doi.org/10.5840/ techne20101416

Brownsword, R. \& Goodwin, M. (2012), Law and the Technologies of the TwentyFirst Century, New York: Cambridge University Press. https://doi.org/10.1017/CBO9781139047609

Council of Europe (2019), Unboxing Artificial Intelligence: 10 Steps to Protect Human Rights, Commissioner of Human Rights.

Crăciunean-Tatu, L.-M. (2018), 'Realizing the right to development: the role of economic, social and cultural rights,' Acta Universitatis Lucian Blaga, no. 1, pp. 28-40. 
Deigh, J. (2010), An Introduction to Ethics, New York: Cambridge University Press. https://doi.org/10.1017/CBO9780511750519

Deloitte (n.d.), Europe's "Trustworthy AI" meets AI Ethics. The ethics of AI. Retrieved from https://www2.deloitte.com/nl/nl/pages/risk/articles/europes-trustworthy-ai-meetsai-ethics.html [accessed Apr 2021]

Ellul, J. (1964), The Technological Society, New York: Vintage Books.

European Commission (2019), Ethics Guidelines for Trustworthy AI, European Commission High-Level Expert Group on Artificial Intelligence. Retrieved from https://ec.europa.eu/futurium/en/ai-alliance-consultation [accessed Apr 2021]

European Disability Strategy 2010-2020: A Renewed Commitment to a Barrier-Free Europe, $\operatorname{COM(2010)~} 636$ final, 15.11.2010. Retrieved from https://ec.europa. eu/eip/ageing/standards/general/general-documents/european-disabilitystrategy-2010-2020_en.html [accessed Apr 2021]

Fares, L. (2019), 'India: A model for the enforcement of economic, social and cultural rights,' Journal of Law and Commerce, vol. 37, no. 2, pp. 281-301. https://doi.org/10.5195/jlc.2019.162

Ferraz, O. L. M. (2008), 'Poverty and human rights,' Oxford Journal of Legal Studies, vol. 28, no. 3, pp. 585-603. https://doi.org/10.1093/ojls/gqn012

Ihde, D. (2020), 'A prelude to Material Hermeneutics (2021),' Acta Baltica Historiae et Philosophiae Scientiarum, vol. 8, no. 2, pp. 5-20. https://doi.org/10.11590/ abhps.2020.2.01

Joamets, K. \& Chochia, A. (2020), 'Artificial intelligence and its impact on labour relations in Estonia,' Slovak Journal of Political Sciences, vol. 20, no. 2, pp. 255-277. http://doi.org/10.34135/sjps.200204

Jobin, A.; Ienca, M. \& Vayena, E. (2019), 'The global landscape of AI ethics guidelines,' Nature Machine Intelligence, vol. 1, pp. 389-399.

https://doi.org/10.1038/s42256-019-0088-2

Johnson, D. (2004), 'Computer ethics,' in L. Floridi (ed.) The Blackwell Guide to the Philosophy of Computing and Information, New York: Blackwell, pp. 65-75.

Kerikmäe, T.; Hoffmann, T. \& Chochia, A. (2018), 'Legal technology for law firms: determining roadmaps for innovation,' Croatian International Relations Review, vol. 24, no. 81, pp. 91-112. https://doi.org/10.2478\%20/cirr-2018-0005

Kerikmäe, T.; Müürsepp, P.; Pihl, H. M.; Hamulák, O. \& Kocharyan, H. (2020), 'Legal person- or agenthood of artificial intelligence technologies,' Acta Baltica Historiae et Philosophiae Scientiarum, vol. 8, no. 2, pp. 73-92. https://doi. org/10.11590/abhps.2020.2.05

Kerikmäe, T.; Müürsepp, P.; Särav, S. \& Chochia, A. (2017), 'Ethical lawyer or moral computer - historical and contemporary discourse on incredulity between the human and a machine,' Visnyk Natsional'noyi akademiyi pravovykh nauk Ukrayiny [Journal of the National Academy of Legal Sciences of Ukraine], vol. 2, no. 89, pp. 27-42. 
Kerikmäe, T. \& Rull, A., eds. (2016), The Future of Law and eTechnologies, Heidelberg: Springer-Verlag. https://doi.org/10.1007/978-3-319-26896-5

Kritikos, M. (2018a), 'What if technologies challenged our ethical norms?' At a Glance, Scientific Foresight: What If? Brussels: European Parliamentary Research Service, STOA, PE 624.246.

Kritikos, M. (2018b), 'What if technologies had their own ethical standards?' At a Glance, Scientific Foresight: What If? Brussels: European Parliamentary Research Service, STOA, PE 624.247.

Latonero, M. (2018), Governing Artificial Intelligence: Upholding Human Rights and Dignity, Data \& Society.

Malgesini, G.; Cesarini-Sforza, L.; Babović, M.; Leemkuil, S.; Sverrisdóttir, M. \& Mareková, S. (2017), Gender and Poverty in Europe, EAPN Briefing Note, EAPN's Women and Poverty Informal Working Group of the EU Inclusion Strategies Group.

Metzinger, T. (2018), 'Towards a global artificial intelligence charter, should we fear the future of artificial intelligence?' in P. J. Bentley, M. Brundage, O. Häggström \& T. Metzinger (eds.) In-depth Analyses, Science and Technology Options Assessment, Brussels: European Parliamentary Research Service, STOA, PE 614.547.

Minkel, L. \& Prakash, N. (2015), The Role of Constitutions on Poverty: A Cross-National Investigation, IZA Discussion Paper no. 8877, February, IZA: Institute of Labor Economics.

OHCHR (n.d.), 'Key concepts on ESCRs: Can economic, social and cultural rights be litigated at courts?' Office of the United Nations High Commissioner of Human Rights. Retrieved from https://www.ohchr.org/EN/Issues/ESCR/Pages/ CanESCRbelitigatedatcourts.aspx [accessed Apr 2021]

OHCHR (2009), Frequently Asked Questions on Economic, Social and Cultural Rights, Fact Sheet no. 33, Office of the United Nations High Commissioner for Human Rights.

Parsons, T. D. (2019), Ethical Challenges in Digital Psychology and Cyberpsychology, Cambridge: Cambridge University Press. https://doi.org/10.1017/9781108553384

Pastor y Camarasa, A. (2016), 'Implementation of economic, social, and cultural rights: perspectives from deliberative democracy,' Trinity College Law Review, vol. 19, no. 1, pp. 214-233.

Rosenberg, R. (2020), 'A preliminary inventory of the transformations of scientific imaging,' Acta Baltica Historiae et Philosophiae Scientiarum, vol. 8, no. 2, pp. 21-37. https://doi.org/10.11590/abhps.2020.2.02

Schwarz, H. (1993), 'Economic and social rights,' American University International Law Review, vol. 8, no. 2, art. 17, pp. 551-565.

Sutrop, M. (2020), 'Challenges of aligning artificial intelligence with human values,' Acta Baltica Historiae et Philosophiae Scientiarum, vol. 8, no. 2, pp. 54-72. https://doi.org/10.11590/abhps.2020.2.04 
UKEssays (2018), Assessing the relationship between law and ethics. Retrieved from https:/www.ukessays.com/essays/business/assessing-the-relationship-between-lawand-ethics-business-essay.php?vref=1 [accessed Apr 2021]

UN (2006), Convention of the Rights of Persons with Disabilities, United Nations General Assembly, A/RES/61/106, 13.12.2006.

Verbeek, P.-P. (2011), Moralizing Technology, Understanding and Designing the Morality of Things, Chicago: University of Chicago Press. https://doi.org/10.7208/chicago/9780226852904.001.0001

Vercelli, A.; Rainero, I.; Ciferri, L.; Boido, M. \& Pirri, F. (2017), 'Robots in elderly care,' Scientific Journal on Digital Cultures, vol. 2, no. 2, pp. 37-50. https://doi. org/10.4399/97888255088954

WHO (2018), 'Assistive technology: key facts,' 18 May. Retrieved from https://www. who.int/news-room/fact-sheets/detail/assistive-technology [accessed 9 Feb 2020]

Winston, M. \& Edelbach, R. (2011), Society, Ethics and Technology, Belmont, CA: Wadsworth Publishing.

Kristi Joamets, PhD is a senior lecturer at TalTech Law School, Tallinn University of Technology. Dr. Joamets obtained her doctoral degree on public administration. She has more than 20 academic publications as articles in peer-reviewed academic journals, chapters in books, and conference papers. Her main areas of research include family law, labour law, education law and social law.

Archil Chochia, PhD is a senior researcher at TalTech Law School, Tallinn University of Technology. He has authored more than 80 academic publications and he is a co-editor of the books Political and Legal Perspectives of the EU Eastern Partnership Policy (Springer, 2016), Brexit: History, Reasoning and Perspectives (Springer, 2018) and Russian Federation in the Global Knowledge Warfare - Influence Operations in Europe and Its Neighbourhood (Springer, 2021). Archil is a senior fellow of Weinstein International Foundation. 